\title{
Expansão da Educação Superior no MERCOSUL: análise do cenário brasileiro, as possibilidades trazidas pela educação a distância e a relevância de bases curriculares transnacionais ${ }^{1}$
}

\author{
Higher Education expansion in MERCOSUR: analysis of the brazilian scenario, \\ the possibilities brought by distance education and the relevance of the \\ transnationals curriculum bases \\ Expansión de Educación Superior en el MERCOSUR: análisis del escenario \\ brasileño, las posibilidades traídas por la educación a distancia y la \\ importancia de bases curriculares transnacionales
}

\author{
WARLLEY FERREIRA SAHB \\ FERNANDO JOSÉ DE ALMEIDA
}

\begin{abstract}
Resumo: Este trabalho realiza uma análise da atual política de integração educacional da América do Sul a partir da conjuntura brasileira, por intermédio da verificação do alargamento da oferta de vagas no ensino superior no Brasil e da análise das ações do Setor Educacional do MERCOSUL (SEM). Aponta, ainda, a potencialidade que os recursos das tecnologias aplicadas à educação e da educação a distância podem ter nesse processo. Para isso, realizou se o cotejamento com o processo de expansão da educação superior na Europa, a partir do Processo de Bolonha e com ações mais recentes neste movimento, como a apresentação do conceito de Mobilidade Virtual (MV) como estratégia para o alcance do objetivo de realizar uma educação transfronteiriça com o apoio da educação a distância. Defende-se também, à guisa de conclusão, que a construção de experiências de bases curriculares transnacionais funcionaria como articuladora dos conhecimentos e das culturas produzidas na América Latina e promotoras de políticas de integração e desenvolvimento regionais.
\end{abstract}

Palavras-chave: Integração educacional; MERCOSUL; bases curriculares; educação a distância; educação superior.

\begin{abstract}
This paper analyzes the current educational policy of integration of South America from the Brazilian perspective, through the verification of the increase of opportunities for the higher education in Brazil, and the analysis of the actions of the Mercosur Educational Sector (SEM). This work also highlights the important role that the technologies resources play when applied to education and distance education. For this purpose, was performed a comparison with the process of expansion of higher education in Europe, by using the Bologna Process and the most recent actions regarding this movement, such as the presentation of the Virtual Mobility (MV) concept as a strategy to accomplish the goal of conducting a cross-border education with the support of distance
\end{abstract}

\footnotetext{
1 Trabalho realizado como etapa de finalização do Doutorado Sanduíche realizado na Universidade Aberta de Portugal (UAb-PT), com apoio da Coordenação de Aperfeiçoamento de Pessoal de Nível Superior (Capes).
} 
education. As a conclusion, this work defends the creation of transnational curriculum bases experiences would function as an articulator of knowledge and cultures produced in Latin America, and as promoters of regional integration and development policies.

Keywords: Educational integration; MERCOSUR; Curricular bases; Distance education; Higher education.

Resumen: Este trabajo realiza un análisis de la actual política de integración educacional de América del Sur a partir de la situación de Brasil, a través de la verificación de la ampliación de la oferta de plazas en la educación superior en Brasil y del análisis de las acciones del Sector Educativo del MERCOSUR (SEM). También apunta la posibilidad que los recursos de las tecnologías aplicadas a la educación y de la educación a distancia pueden desempeñar en este proceso. Para esto, se realizó el cotejamiento con el proceso de expansión de la educación superior en Europa, desde el Proceso de Bolonia y con las acciones más recientes en este movimiento, como la presentación de concepto de Movilidad Virtual (MV) como estrategia para alcanzar la meta de realizar una educación transfronteriza con el apoyo de la educación a distancia. Se defiende también, a modo de conclusión, que la construcción de experiencias de bases curriculares transnacionales funcionaría como articuladora de los conocimientos y de las culturas producidas en América Latina y promotoras de políticas de integración y desarrollo regionales.

Palabras clave: Integración educativa; MERCOSUR; Bases curriculares; Educación a distancia; Educación Superior.

\section{INTRODUÇÃO}

Praticamente resolvida no Brasil, a questão do acesso à educação básica (ensino fundamental e ensino médio) - conforme se verifica na Figura 1, abaixo, a taxa de escolarização das crianças de 6 a 14 anos de idade vem aumentando de forma ascendente desde 2001, com pequena queda no ano de 2003, tendo sido de 98,2\% em 2011 e 2012 - agora o foco passa ser o da oferta de educação com qualidade para todos.

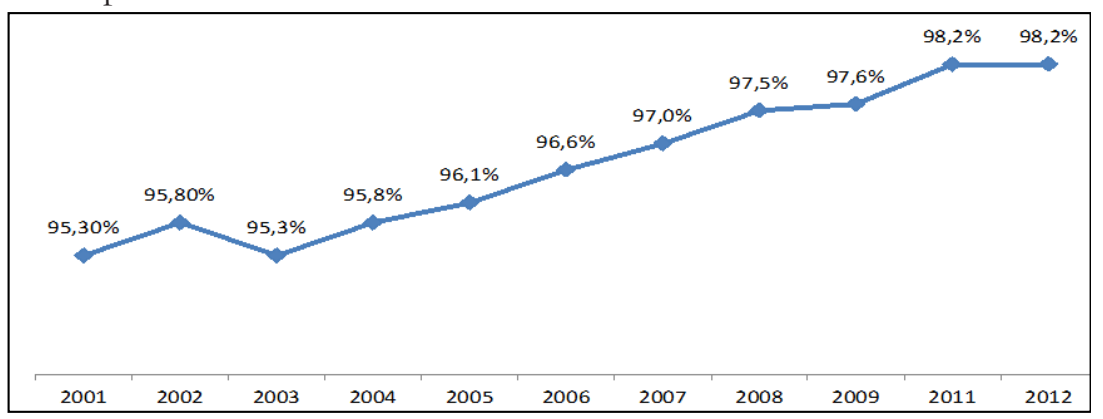

Figura 1 - Taxa de frequência à escola - população de 6 a 14 anos - Brasil 2001/2012. Fonte: Brasil (2014b)

628 - RBPAE - v. 31, n. 3, p. 627 - 648 set./dez. 2015 
Esse processo de alargamento de acesso e frequência à educação básica é importante no quadro nacional, pois, conforme Belloni (2012), associado a outros fatores tais como o crescimento econômico, a industrialização e a consequente necessidade de capacitação continuada, vai colaborar para o aumento de demanda de vagas no ensino superior. Como ilustração desse quadro, podemos lançar mão da Figura 2 abaixo, que traz a demonstração da evolução da taxa de escolarização da Educação Superior no Brasil, considerando-se os anos de 2003 a 2012. Vejamos:

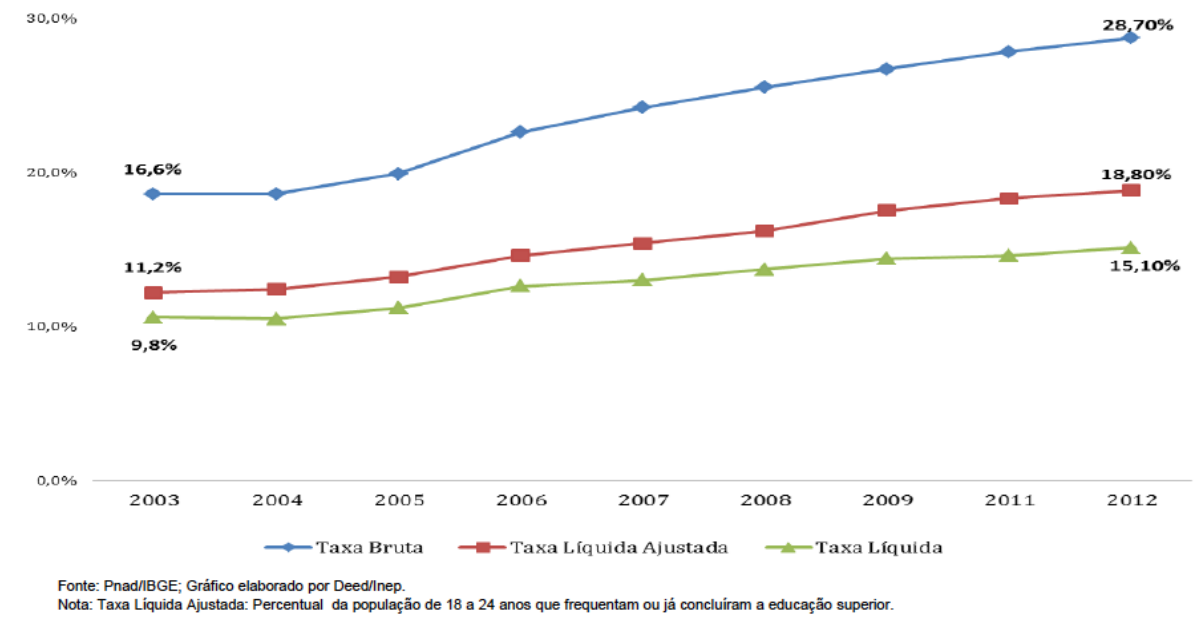

Figura 2: Evolução da taxa de escolarização da Educação Superior no Brasil - 2003/2012 Fonte: MEC/INEP, 2014.

Esses dados possuem relação direta com o processo de expansão da oferta de educação superior, mas também estão ligados a um processo nacional de expansão regional dessa etapa de formação. Recentemente, temos assistido a esse fenômeno da educação superior como opção de política pública de combate à desigualdade social e de fomento ao acesso à educação superior. A Figura 3, abaixo, traz esse crescimento, característico desse processo de expansão regionalizada: 


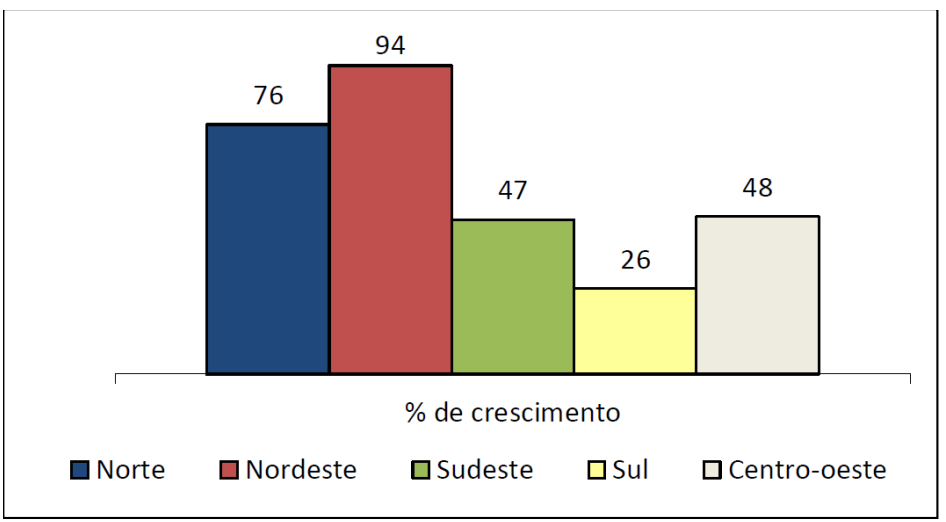

Figura 3 - Crescimento de matrículas nas Universidades por região geográfica - Brasil 2003/2013. Fonte: Brasil (2015).

Já na Figura 4, apresentamos em números essa evolução de matrículas em cursos superiores presenciais e a distância no Brasil.

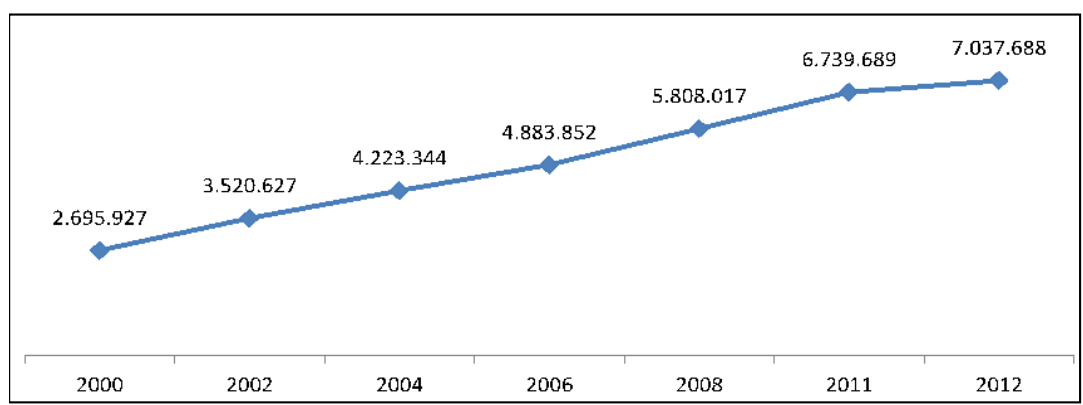

Figura 4 - Evolução do número de matrículas no ensino superior (presencial e a distância) - Brasil 2000/2012. Fonte: Brasil (2014b).

Iniciamos este trabalho por esta breve introdução e descrição do cenário educacional brasileiro para, em seguida, abordarmos o processo de expansão, o potencial e a importância do fomento de um sistema de educação que seja transnacional na América do Sul, à luz do que ocorreu no processo de internacionalização da educação superior na Europa, e o papel estratégico que a EaD pode ter nesse cenário. Para isso, neste trabalho, abordar-se-ão: a) breve histórico da EAD no Brasil; b) o processo de internacionalização da educação no Mercado Comum do Sul (MERCOSUL), por intermédio das ações propostas e desenvolvidas pelo Setor Educacional do MERCOSUL (SEM) e as metas e ações propostas apresentadas para o Brasil em seu Plano Nacional de Educação 2011-2020 (BRASIL, 2014a); c) os trabalhos acerca das mudanças organizacionais e gerenciais inerentes e necessárias nesse processo e, por fim, d) as mudanças 
que podem ser necessárias no currículo relativo à Educação Superior. O objetivo é trazer à discussão o papel que pode desempenhar, nesse complexo sistema transfronteiriço, a expansão da educação a distância que favoreça o alargamento da oferta de vagas, a mobilidade entre os agentes dessa rede com a melhoria da qualidade de aprendizagem.

\section{A EDUCAÇÃO A DISTÂNCIA NO BRASIL: BREVE HISTÓRICO E SEU PROCESSO DE EXPANSÃO}

Dentro do contexto da demanda pela Educação Superior no Brasil, como em outras regiões do mundo, a Educação a Distância (EaD) vem firmandose como opção para inclusão educacional, digital e social que pode contribuir estrategicamente para qualificação de profissionais a serem preparados para o mercado de trabalho, para ajudar a sanar a necessidade de formação de professores e, também, para proporcionar um processo de expansão da oferta de educação superior, tanto no que se refere ao processo de interiorização quanto à internacionalização da educação e da economia.

No Brasil, a modalidade EaD tem seu marco regulatório ancorado no Decreto no 5.622 de 19 de dezembro de 2005, onde esta é definida, em seu artigo $1^{\mathrm{o}}$, como

\footnotetext{
Uma modalidade educacional na qual a mediação didático-pedagógica nos processos de ensino e aprendizagem ocorre com a utilização de meios e tecnologias de informação e comunicação, com estudantes e professores desenvolvendo atividades educativas em lugares ou tempos diversos. (BRASIL, 2005)
}

Contudo, anteriormente ao decreto supracitado, a Lei de Diretrizes e Bases de 1996 (BRASIL, 2002, p. 17), em seu artigo 80, já se posicionava em relação à educação a distância, preconizando que "O Poder Público incentivará o desenvolvimento e a veiculação de programas de ensino a distância, em todos os níveis e modalidades de ensino, e de educação continuada".

Giolo (2008), assim se pronuncia em relação ao alcance e importância da LDB para educação a distância, afirmando que esta “(...) concedeu estatuto de maioridade para educação a distância. Garantiu-lhe o incentivo do poder público, espaço amplo de atuação (todos os níveis e modalidades) e tratamento privilegiado no que se refere à utilização de canais de radiodifusão" (p.1212-1213).

A educação a distância no Brasil contou com um processo de expansão potencializado pela rede privada de ensino. Muitos fatores podem explicar esse fenômeno, como a possibilidade de redução de custos possibilitada pela oferta de 
cursos nessa modalidade - marcada pelo apelo fácil da lotação de turmas ou pelo baixo atendimento educacional ao aluno - ou, mesmo, pela maior flexibilidade de mudanças e adaptações às condições de mercado, peculiares às instituições particulares em comparação ao sistema público de ensino superior no Brasil.

Muito embora a rede privada de ensino ainda detenha grande parte do número de matrículas nessa modalidade de ensino, essa expansão também vem ocorrendo na rede pública. Esse processo de expansão da EaD no Brasil pode ser verificado por meio da análise dos dados da Tabela 1 , abaixo.

Tabela 1 - Evolução do número de matrícula em cursos a distância Brasil 2002 a 2012

\begin{tabular}{|c|c|c|c|}
\hline Ano & Total & Rede Pública & Rede Privada \\
\hline 2002 & 40.714 & 34.322 & 6.392 \\
\hline 2003 & 49.913 & 39.804 & 10.107 \\
\hline 2004 & 59.613 & 35.989 & 23.622 \\
\hline 2005 & 114.642 & 54.515 & 60.127 \\
\hline 2006 & 207.206 & 42.061 & 165.145 \\
\hline 2007 & 369.766 & 94.209 & 275.557 \\
\hline 2008 & 727.961 & 278.988 & 448.973 \\
\hline 2009 & 832.125 & 172.696 & 665.429 \\
\hline 2010 & 930.179 & 182.602 & 748.577 \\
\hline 2011 & 992.927 & 177.924 & 875.003 \\
\hline 2012 & 1.113 .850 & 181.624 & 932.226 \\
\hline
\end{tabular}

Fonte: Elaborada pelo autor com base nos dados do Censo da Educação Superior de 2002 a 2012.

Independentemente de esse processo de expansão ocorrer no âmbito de instituições privadas ou públicas de ensino, é importante ressaltar o aumento de aproximadamente $2.735 \%$ ao longo desses dez anos em análise na tabela, contra $532 \%$ de aumento na rede pública. Com base nos dados do balanço social da Secretaria de Educação Superior (SESU) do Ministério da Educação (MEC), publicado em documento intitulado "A Democratização e a expansão da educação superior no país 2003-2014" (BRASIL, 2015), o número total de matrículas em cursos de graduação a distância é de 1.573 .573 , aumento de mais 460.000 vagas em relação ao ano de 2012.

Papel destacado nesse processo possui a iniciativa pública de criação de um sistema consorciado de oferta de cursos na modalidade a distância e, no âmbito de uma política nacional de formação de professores, foi instituído, pelo Decreto $\mathrm{n}^{\circ} 5.800$ de 8 de junho de 2006, o Sistema Universidade Aberta do Brasil (UAB), integrado por instituições públicas responsáveis pela oferta de cursos superiores com a finalidade de expandir e interiorizar a oferta de cursos e programas de

632 - RBPAE - v. 31, n. 3, p. 627 - 648 set./dez. 2015 
educação superior no País. Conforme o artigo $1^{\circ}$ do decreto instituidor do Sistema UAB, seus principais objetivos são oferecer, prioritariamente, cursos de licenciatura e de formação inicial e continuada de professores da educação básica; cursos superiores para capacitação de dirigentes, gestores e trabalhadores em educação básica dos estados, do Distrito Federal e dos municípios; ampliar o acesso à educação superior pública e estabelecer um amplo sistema nacional de educação superior a distância.

$\mathrm{Na}$ Figura 5, abaixo, pode-se demonstrar a evolução do número de matrículas no Sistema UAB, que mostra um aumento entre os anos de 2007 e 2012 e pequeno decréscimo no ano de 2013. Esta evolução é resultado da adesão ao sistema de 103 Instituições de Ensino Superior (IES) públicas, dentre as quais 56 Universidades Federais, 30 Universidades Estaduais e 17 Institutos Federais de Educação, Ciência e Tecnologia. Em investimento financeiro, segundo dados de agosto de 2013, o aporte de recursos já passa dos $\mathrm{R} \$ 2.270 .000 .000,00$, entre pagamentos de bolsas e investimento em custeio das ações nas IES, o que demonstra a aposta numa política pública para expansão da oferta de vagas no ensino superior, seja em formação inicial (cursos de graduação) ou na formação continuada (cursos de pós-graduação, extensão universitária ou aperfeiçoamento).

Figura 5 - Evolução do número de matrículas no Sistema UAB 2007/2013.

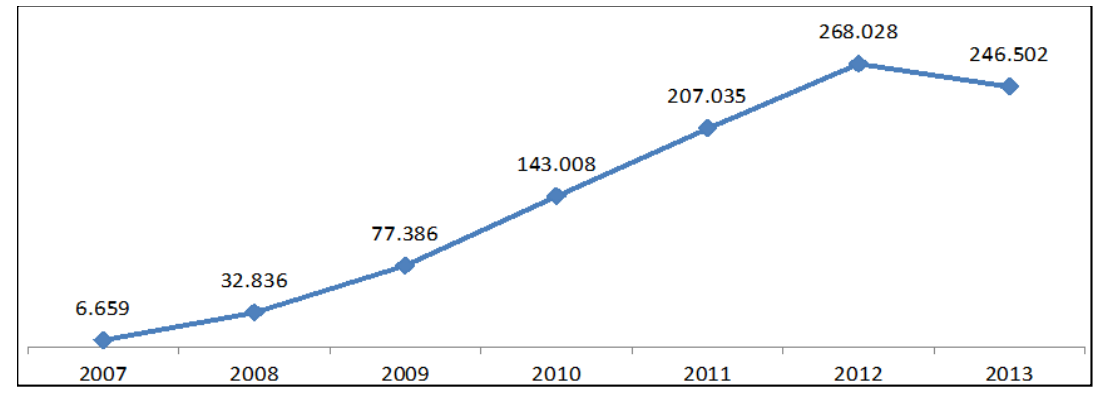

Fonte: Brasil (2014b).

Almeida, Iannone, Silva e Villarinhos (2012) enfatizam que a instituição do Sistema UAB se deve, ainda, a uma resposta à expansão de cursos oferecidos por instituições particulares isoladas ou consorciadas que se constituíam com diversos objetivos, que poderiam não ser, propriamente, o da qualidade dos cursos oferecidos. Contudo, independentemente dos fatores que levaram a essa expansão, o fato é que ela está presente e tem impacto destacado no cenário educacional brasileiro; leva, ainda a tratarmos este alargamento da $\mathrm{EaD}$ como fator de impulso e possibilidade de trabalho visando ao processo de internacionalização da educação na América Latina. 
Esse processo é tratado no âmbito do PNE 2011-2020 e em documentos orientadores do Setor Educacional do MERCOSUL, como citado anteriormente. No próximo tópico, traremos algumas dessas orientações, metas e estratégias, com o intuito de discutir o potencial da EaD, considerando que a educação desempenha papel estratégico no fortalecimento de políticas de integração regional.

\section{O PROCESSO DE INTEGRAÇÃO EDUCACIONAL NO MERCOSUL}

No âmbito do processo de implementação de políticas públicas e ações que têm como objetivo a redução das desigualdades socioeconômicas e educacionais e o fortalecimento das relações comerciais transfronteiriças, pode-se destacar, na América do Sul, o Mercado Comum do Sul (MERCOSUL).

O MERCOSUL é um projeto de integração fundado em 1991 por Argentina, Brasil, Paraguai e Uruguai. Em 2012, a Venezuela e, em 2013, a Bolívia passam também a integrar o bloco. Além dos países membros, Chile, Peru, Colômbia e Equador, além de Guiana e Suriname são Estados Associados do MERCOSUL, status que adquiriram em julho de 2013. Todos os países da América do Sul estão vinculados ao MERCOSUL, seja como Estado Parte, seja como Associados. A Figura 6 abaixo representa, em uma linha do tempo, o histórico legal de ações referentes à criação e à estruturação do MERCOSUL.

\section{Figura 6 - Linha do tempo MERCOSUL.}

\section{Línea del Tiempo}

Textos Fundacionales

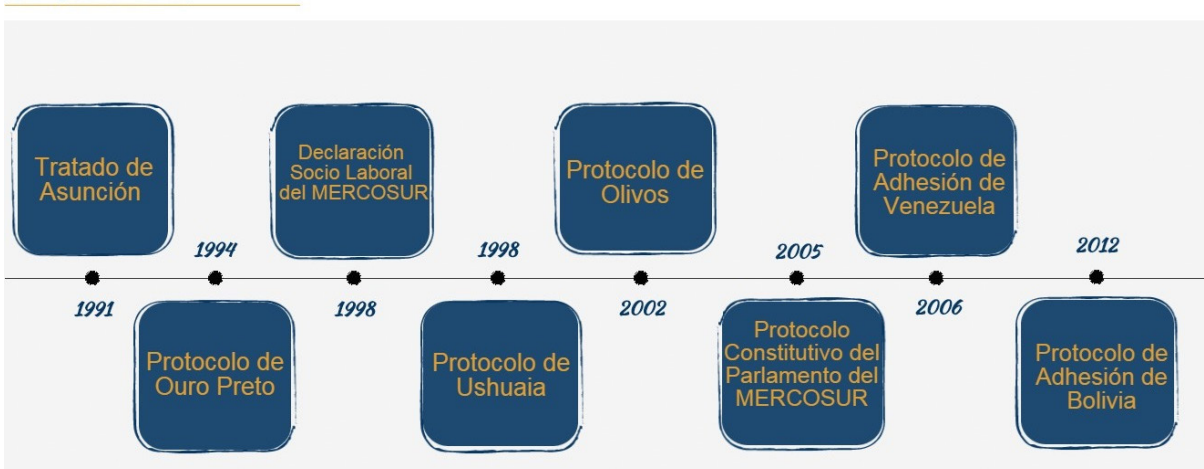

Fonte: Secretaría del MERCOSUR - http://www.mercosur.int/

Evidentemente, a criação do bloco sul-americano de países encontra-se pautado no cenário mundial de expansão e globalização da economia e também 
tem como referência a criação do espaço comum europeu. Conforme Praxedes e Piletti (1997), no início muito pouco se informou nos meios de comunicação sobre o contexto de criação do MERCOSUL. Segundo esses autores: "Da maneira pela qual as notícias sobre o Mercosul são divulgadas na televisão e nos jornais, parece que é um acontecimento sem história, como se fosse apenas resultado da atuação dos quatro governos atuais dos países envolvidos" (PRAXEDES; PILETTI, 1997, p. 32). Contudo, eles mesmos tratam de alargar esse entendimento inicial: "Não é bem assim. Na realidade, se hoje se fala em organizar um mercado comum no Cone Sul da América é porque a formação de um bloco econômico na região é uma exigência do capitalismo globalizado" (Ibidem), de baixo impacto financeiro mas de amplo significado político e cultural.

O MERCOSUL se sustenta em três pilares: o econômico comercial, o social e o da cidadania, sendo composto por grande diversidade de órgãos, os quais cuidam de temas variados, como agricultura familiar, direitos humanos, gênero, saúde e outros. $\mathrm{Na}$ dimensão da cidadania, trabalha-se para a progressiva implantação de políticas que permitam a livre circulação de pessoas e a promoção de direitos civis, sociais, culturais e econômicos para os países do bloco, bem como a garantia de igualdade de condições e de acesso ao trabalho, saúde e educação.

Como área de interesse estratégica na ligação entre economia, trabalho e cidadania, ganha espaço o tratamento da questão educacional, nomeadamente visando a gerar competitividade entre as economias. Nesse sentido, Praxedes e Piletti (1998) também se posicionam: "O Mercosul, organizado com vistas a incrementar a competitividade dos setores econômicos mais dinâmicos dos países envolvidos, está oportunizando a reintrodução da educação enquanto fator importante para as estratégias empresariais" (p. 223).

Entretanto, há que se destacar que esses mesmos autores fazem uma ressalva quanto a esse processo de discussão acerca da importância da educação na integração do bloco. Destacam que o tratamento dado às questões educacionais remete à Teoria do Capital Humano, "reintegrando no debate atual uma abordagem economicista e de sentido liberalizante" (Idem, p. 231). E seguem, completando essa análise:

Entretanto, mesmo nessa perspectiva economicista, as iniciativas adotadas no campo educacional revestem-se de acentuada fragilidade, na medida [em] que priorizam aspectos formais e credencialistas, dispensando pouca ou nenhuma atenção ao próprio conteúdo de educação. Em face das limitações da perspectiva que condiciona a legitimidade social dos sistemas educacionais à sua rentabilidade econômica para os grupos empresariais, bem como da fragilidade das primeiras iniciativas empreendidas, entendemos ser necessário que novas alternativas passem a hegemonizar o debate e as práticas educacionais no âmbito do processo de integração entre os países do Mercosul. (Idem, p. 232) 
Mais detidamente, no que se refere ao processo de integração educacional no âmbito do MERCOSUL, o bloco criou, em 1991, o Setor Educacional do MERCOSUL (SEM), que tem como função trabalhar planos e ações que tratem da inclusão e qualidade da educação nos países membros. A missão deste setor é

Formar um espaço educacional comum, por meio da coordenação de políticas que articulem a educação com o processo de integração do MERCOSUL, estimulando a mobilidade, o intercâmbio e a formação de uma identidade e cidadania regional, com o objetivo de alcançar uma educação de qualidade para todos, com atenção especial aos setores mais vulneráveis, em um processo de desenvolvimento com justiça social e respeito à diversidade cultural dos povos da região. (MERCOSUL, 2012, p. 10)

E, ainda, o SEM também se insere no contexto de fortalecimento das políticas de integração regional, nas quais "a educação desempenha um papel estratégico" (Idem, p.4). Nesse sentido, o SEM passa a ser instrumento essencial para a construção de um espaço educacional integrado, na medida em que se propõe realizar a coordenação das políticas públicas de educação no espaço do bloco.

Como forma de planejar suas ações em busca do cumprimento de seu objetivo, o SEM se organiza em torno de um Plano de Ação do SEM, que se

Insere em um novo contexto internacional e regional. No âmbito internacional destacam-se as mudanças nas relações políticas, comerciais e financeiras ocorridas após a crise econômica de 2008, que teve seus efeitos mais impactantes nos países da América do Norte e Europa. (MERCOSUL, 2012, p.3)

Para a construção desse espaço educacional integrado, o SEM trabalha com a perspectiva de consolidação da educação como direito humano e bem público e social. Nesse sentido, vem realizando diversos avanços nos ordenamentos jurídicos dos países da região e vem alcançando progresso também nos níveis de cobertura educacional, sempre aliado ao incremento de qualidade (Idem).

Considerando um levantamento realizado em 2009, que mostra a taxa líquida de escolarização em nível superior nos países membros do MERCOSUL no mesmo ano, pode-se ver que esse processo de integração deverá enfrentar, antes, o desafio de aumentar a oferta de vagas e promover a permanência de seus cidadãos no ensino superior, tendo em vista que o país com maior taxa líquida de pessoas com formação superior é o Chile, com 30,8\%, e o mais baixo é o Brasil. Segue a Tabela 2 com alguns dados: 
Tabela 2 - Taxa Líquida de Escolarização terciária segundo países - 2009

\begin{tabular}{|c|c|}
\hline País & Taxa (\%) \\
\hline Argentina & 25,1 \\
\hline Brasil & 14,6 \\
\hline Chile & 30,8 \\
\hline Paraguai & 18,2 \\
\hline Uruguai & 20,3 \\
\hline
\end{tabular}

Fonte: Mercosul (2009).

Depreende-se desse cenário trazido pelos dados apresentados acima que há, de fato, um ambiente capaz de comportar e exigir um processo de expansão, integração e qualidade da educação superior e, nesse aspecto, a educação a distância pode ser utilizada como estratégia para atingir esse fim. A posição acima supõe, e este é o escopo de nosso artigo, que se demonstrem as qualidades formativas e cidadãs dos programas educativos em regime EAD.

Contudo, para tornar propício esse ambiente de oferta de cursos superiores transnacionais e de forma integrada, algumas medidas vêm sendo planejadas, fomentadas e implantadas pelo SEM. Ademais, ainda outros dois objetivos podemos destacar como estratégicos desse setor: a) promover e fortalecer os programas de mobilidade de estudantes, estagiários, docentes, pesquisadores, gestores, diretores e profissionais e b) acordar políticas que articulem a educação como processo de integração do MERCOSUL. Devem ser mencionadas também as ações vinculadas à educação em direitos humanos, educação ambiental, educação para a primeira infância, educação de jovens e adultos, educação profissional e tecnológica, educação e diversidade e educação a distância, que, no Plano 20112015 serão consolidadas e estruturadas. (MERCOSUL, 2012)

Do ponto de vista do financiamento das ações desse setor, destaca-se a criação do Fundo de Financiamento do Setor Educacional do MERCOSUL (FEM) que "servirá como instrumento para a continuidade das ações do Setor, até então financiadas por iniciativas pontuais dos Ministérios de Educação dos países participantes e organismos internacionais". (Idem, p. 6)

Ainda destacam-se como ações do SEM o estabelecimento de contatos e relações com outros blocos e organizações internacionais, tais como Organização de Estados Ibero-Americanos (OEI), União de Nações Sul-Americanas (UNASUL), União Europeia (EU), Organização das Nações Unidas para a Educação, a Ciência e a Cultura (UNESCO), Organização dos Estados Americanos (OEA), Instituto de Avaliação e Acompanhamento das Metas Educacionais 2021 (IESME), Comunidade dos Estados Latino-americanos e Caribenhos (CELAC) e Sistema de Informação de Tendências Educacionais na América Latina (SITEAL). 
O objeto do estabelecimento de tais contatos ou relações é o de contribuir para a consolidação do processo de integração regional, de modo a apoiar o processo de melhoria da qualidade da educação e consolidar um espaço de coesão social.

Algumas ações já são fruto dos trabalhos realizados entre o SEM e os diversos organismos parceiros acima citados. Como exemplos, podemos destacar: o Programa Mobilidade Acadêmica Regional para os Cursos Acreditados pelo Mecanismo de Acreditação de Cursos Superiores no MERCOSUL (MARCA); o Programa de Associação Universitária para a Mobilidade de Docentes do Ensino Superior do MERCOSUL; o Programa de Intercâmbio Acadêmico de Português e Espanhol e o Projeto de Apoio da União Europeia ao Programa de Mobilidade do MERCOSUL na Educação.

Em relação às ações finalísticas nesse processo de expansão e integração da educação no MERCOSUL, deve-se dar destaque à condução de um processo de acreditação de cursos superiores, com a conclusão do Mecanismo Experimental de Acreditação (MEXA) e a realização do Seminário de Avaliação do MEXA, momento em que foi criado o Plano Operativo para a implementação do Sistema de Acreditação de Cursos Universitários do MERCOSUL (ARCU-SUL).

Aos moldes do processo de integração do sistema de ensino superior realizado na Europa, por intermédio do Processo de Bolonha, que "induziu a uma mudança a nível dos sistemas através da implementação de instrumentos que contribuem para gerar confiança, que visam aumentar a transparência entre as jurisdições nacionais e que permitem a convergência de sistemas" (EUROPEAN COMISSION, 2013, p. 10) e que inclui ainda o Sistema Europeu de Transferência de Créditos (ECTS), o ARCU-SUL iniciou suas atividades contando com a adesão de sete países e realiza seu processo de avaliação e acreditação também em sete áreas, quais sejam: Agronomia, Arquitetura, Enfermagem, Engenharia, Medicina, Odontologia e Veterinária (MERCOSUL, 2012).

Sobre o ARCU-SUL, Legoria (2013) afirma que esse sistema vem como uma iniciativa que visa a "promover a acreditação de cursos de graduação na região, considerando-se um elemento essencial para melhoria da qualidade da educação superior e um avanço para o processo de integração regional" (p. 74 - tradução nossa). E, ainda, para esta mesma autora, o ARCU-SUL tem como objetivo principal

Constituir-se como um critério comum para facilitar o reconhecimento mútuo de diplomas de cursos superiores para o exercício profissional em convênios, tratados ou acordos bilaterais, multilaterais, regionais ou sub-regionais celebrados com esse fim. (Idem, p. 75 - tradução nossa) 
Entretanto, é preciso destacar que todas essas ações desenvolvidas em nível internacional com o apoio desse setor específico criado no âmbito do MERCOSUL devem contar com o correspondente respaldo dos países membros no sentido de que estes façam uma adesão ao processo de alargamento da educação transnacional. Para isso, faz-se necessária uma série de medidas para que se adequem as legislações educacionais nacionais ao compasso de ação do SEM. No caso brasileiro, podemos notar um movimento mais amplo, alinhado às propostas do Plano de Ação do Setor Educacional do MERCOSUL 2011-2015, por meio das propostas constantes do Plano Nacional de Educação (BRASIL, 2014a).

Como exemplo desse esforço, podemos destacar uma das metas do Plano, a de número 12, que objetiva "elevar a taxa bruta de matrícula na educação superior para 50\% (cinquenta por cento) e a taxa líquida para 33\% (trinta e três por cento) da população de 18 (dezoito) a 24 (vinte e quatro) anos" (Idem).

Em relação ao processo de internacionalização da educação, podemos trazer ainda dentro da meta doze, nomeadamente a estratégia 12.12, a saber: "consolidar e ampliar programas e ações de incentivo à mobilidade estudantil e docente em cursos de graduação e pós-graduação, em âmbito nacional e internacional, tendo em vista o enriquecimento da formação de nível superior" (BRASIL, 2014a). Outras metas e estratégias trarão a preocupação com a expansão e internacionalização das redes de pesquisa e dos cursos de pós graduação que, assim como no caso da expansão dos cursos de graduação, podem contar com a educação a distância como opção para a realização desse seu fim.

\section{MUDANÇAS NECESSÁRIAS PARA EXPANSÃO DA OFERTA E DA MOBILIDADE: BREVES DISCUSSÕES E AS POSSIBILIDADES TRAZIDAS PELA TECNOLOGIA}

Para se adequarem a esse processo de expansão e de internacionalização, as instituições de ensino superior necessitam de um momento de planejamento, de reflexão e de transformação, sobretudo se tomarmos em conta dois aspectos básicos: 1) a aceleração do tráfico de informações impactando o processo de ensino-aprendizagem e 2) os processos decisórios necessários à administração destas.

Esses processos passam a exigir mudanças nas estruturas acadêmicas e administrativas das instituições de ensino: mudanças pedagógicas, trazidas, por exemplo, pelos recursos educacionais abertos (REA) e mudanças no processo de gestão institucional, como alteração nos quadros de pessoal, abertura e conectividade e a consequente exigência de trabalho em rede. 
Nesse ínterim, o uso das tecnologias digitais da informação e comunicação (TDICs) aplicadas à educação vem ganhando importância e espaço no âmbito da educação superior. Nesse cenário, não basta desenvolver e implantar soluções tecnológicas; é preciso que se considere um novo modo de trabalhar. Um modo que leve em conta a necessidade premente de mediação pedagógica também inovadora, que incorpore esses avanços tecnológicos sem deixar de lado o trabalho coletivo.

Neste latente cenário de mudanças, Teixeira (2012) se insere na discussão e apresenta a necessidade de desconstrução e reconstrução da universidade. Segundo esse autor,

O modo como as universidades têm respondido ao desafio colocado pela sociedade em rede caracteriza-se por uma aposta no crescimento da conectividade e também pelo aumento da personalização, participação e transparência dos seus serviços. Entre estas características, [...] identifica[-se] claramente como prioritária e crítica para o desenvolvimento estratégico das instituições universitárias a aposta no alargamento da abertura, uma vez que entende esta dimensão como um pré-requisito para o avanço nas outras três áreas. Uma maior abertura, não apenas do conteúdo, mas das plataformas e recursos, permite escalar a um custo aceitável as restantes dimensões referidas atrás. (TEIXEIRA, 2012, p. 6)

E ainda, para o autor (Idem, p. 8), “a adoção generalizada de práticas educacionais abertas comporta consequências importantes, as quais conduzirão necessariamente a uma transformação radical das culturas organizacionais das instituições de ensino superior". Por isso, pode-se falar neste processo de uma mudança, que consiste na desconstrução do modelo tradicional de gestão institucional centrado em "esquemas hierárquicos primordialmente centrados na expertise individual" (p. 10) para um consequente processo de reconstrução dessas instituições, pautado em "novos modelos organizacionais universitários mais ágeis e capazes de responder rapidamente aos desafios externos, reajustando a organização a um ritmo cada vez mais rápido” (p. 9).

Cabe às instituições universitárias, nesse contexto, profunda vigilância sobre a adequação das novas exigências da contemporaneidade a suas finalidades maiores. Tais percursos, na direção do atendimento às inovações e ampliação do atendimento, serão guiados pelos tradicionais escopos do trabalho universitário: a partilha e construção do conhecimento humano numa visão crítica e instrumental.

No que diz respeito aos processos pedagógicos, fazem-se necessárias mudanças institucionais, além de mudanças que proporcionem aos sistemas educacionais nacionais a convergência necessária para um movimento integrativo e transnacional, de processos transparentes e confiáveis de avaliação e certificação. No caso do processo europeu, alguns marcos decisórios foram fundamentais para 
sua consolidação. Dentre estes, destacam-se: o desenvolvimento de um quadro geral de qualificações para o espaço europeu no âmbito profissional e de mercado de trabalho; o Sistema Europeu de Transferência de Créditos (ECTS) e a adoção de processos avaliativos garantidores de qualidade da educação.

Uma ação de potencial impacto que se aplica ao processo de alargamento de opções à mobilidade física no Espaço Europeu de Ensino Superior (EEES), a Mobilidade Virtual, (MV), é considerada uma estratégia nesse processo de transposição de barreiras geográficas, para além da mobilidade incentivada no PNE 2011/20120 no Brasil ou no Plano de Ação do Setor Educacional do MERCOSUL 2011-2015.

A MV pode ser entendida como um novo conceito:

\begin{abstract}
A combinação de e-learning e de mobilidade levou ao desenvolvimento de um novo conceito: a mobilidade virtual (VM), definido pela elearningeuropa. info como "o uso das tecnologias da informação e da comunicação (TIC) para obter os mesmos benefícios que um teria com mobilidade física, mas sem a necessidade de deslocamento. (TEIXEIRA, MIRANDA e DIAS, 2011, p. 1003 - tradução nossa).
\end{abstract}

$\mathrm{Ou}$ seja, no momento em que ganha importância nesse processo de transpassar fronteiras educacionais o fomento a ações que promovam a mobilidade de estudantes, contar com a opção da VM pode ser fundamental, tendo em vista que os processos de mobilidade física e mobilidade virtual podem ser complementares ou coexistentes. Esse entendimento é corroborado por Teixeira, Miranda e Dias, quando dizem que

\begin{abstract}
A MV é realmente uma estratégia efetiva para organizar a mobilidade em grande escala. No entanto, devemos perceber que esta forma virtual de mobilidade não é apenas um substituto mais barato para um programa de intercâmbio real, é uma forma diferente de permitir a uma gama de estudantes alcançarem os mesmos objetivos da mobilidade física, tais como: ganho de experiência internacional e competência para obterem outras oportunidades de estudo, muitas vezes mais especializadas. (Idem, p. 1005 - tradução nossa).
\end{abstract}

No caso do processo de integração educacional do MERCOSUL, conduzido pela SEM, no momento em que a indução desse processo de mobilidade se inicia e ganha impulso, torna-se estratégico contar também com essa opção de fomento à mobilidade virtual e, com isso, utilizar-se de todas as ferramentas e alternativas trazidas pela educação a distância passa a ser uma ação política importante de todos os países participantes.

Assim, no Plano de Ação do Setor Educacional do Mercosul 20112015, alguns alinhamentos estratégicos vêm ao encontro desse objetivo de 
promoção de mobilidade e diversificação de meios para concretizá-la. Dente estes, podemos destacar um, a saber: "Promover e fortalecer os programas de mobilidade de estudantes, estagiários, docentes, pesquisadores, gestores, diretores e profissionais" (MERCOSUL, 2012, p. 16), o qual traz ao menos dois objetivos específicos: 1) Fortalecimento e manutenção de programas de mobilidade de estudantes de graduação na região e 2) Promoção e incentivo a novas iniciativas para a mobilidade dos distintos atores dos sistemas educacionais na região.

Ademais, aumentar o número de cursos, estabelecer mecanismos de reconhecimento de créditos, considerar um padrão mínimo de proficiência no que se refere às diferentes línguas, padronizar procedimentos administrativos, implantar um processo transparente de informações aos estudantes interessados, contar com um ou mais mecanismos de financiamento são ações importantes para a viabilização dessa transposição de barreiras e internacionalização da educação no MERCOSUL. Ao se reconhecer a importância e a possibilidade de a EaD contribuir nesse processo, é necessário incluí-la nessas discussões, de modo que se evite raciocinar a partir de processos díspares que afastem educação presencial de educação a distância, mesmo considerando-se as especificidades metodológicas da EaD.

Entretanto, destaque-se ainda que esse processo de transposição de fronteiras, no que diz respeito à educação, trará consigo uma série de outras mudanças que se imporão nesse cenário, haja vista o que vem sendo observado no processo de internacionalização da educação em curso no espaço europeu. Disso trataremos a seguir, incorporando também as alterações das práticas curriculares, atreladas de forma expressa às questões de promoção e de incentivo à expansão e à mobilidade.

\section{BASES CURRICULARES TRANSNACIONAIS PARA O MERCOSUL}

A pirâmide de programas e projetos que se constituiu a partir das ações de fundação do MERCOSUL tende a construir blocos que se agregam por interesses, às vezes circunstanciais, às vezes estruturantes de um sistema. Por ser um organismo vivo, formado por estados-nação sempre em mudanças, ora de caráter político ora econômico, as marchas e contramarchas daí oriundas tendem a volatilizar-se como políticas de longo prazo, que desmancham ou fragmentam seu caráter sistêmico.

A partir da consciência destas flutuações nervosas dos blocos políticos, os organismos e os eixos estruturantes de ações em longo prazo devem articularse em torno de conceitos que construam consensos mais duradouros. $\mathrm{Na}$ área da educação, este artigo defende que o empenho para que se criem e consolidem 
eixos curriculares com os países membros, seja a um só tempo, uma premissa e uma urgência.

Enfatiza-se aqui o procedimento político pelo qual se deu o início da construção da Comunidade Europeia como organismo econômico e cultural: a constituição do Tratado de Bolonha. Construído com as mãos de todos os parceiros dos países envolvidos, seus objetivos eram, em ponto maior, os mesmos do Mercosul: trânsito cultural, desenvolvimento e racionalização da economia; redução das estruturas burocráticas que embargavam a agilidade de trocas e a redução de custos; a racionalização dos intercâmbios sociais, mobilidade entre nações e culturas etc. Tudo teria que partir de uma unidade ou de um consenso curricular e neles [na unidade e no consenso] culminar.

O Euro, moeda única, foi o fator mais evidente dessa busca, mas o currículo orgânico, claro e preciso, foi seguramente um dos criadores de um consenso entre as nações. Partia-se do princípio de que a formação e a consolidação de suas uniões viriam das trocas culturais e dos conhecimentos gerados e divulgados entre elas.

Nesse sentido, este artigo defende a necessidade de se ampliar o debate, no interior do MERCOSUL, sobre as bases curriculares latino-americanas da formação integrada para a educação, cultura, ciência e tecnologias no interior das ações políticas. Os programas de EAD que já se iniciam em dimensão de velocidade e qualidade tecnológicas devem estar alinhados com os currículos integradores, facilitando o fluxo de alunos, a mobilidade de profissionais, a identificação dos programas com a cultura e os interesses de qualidade, democracia, identidade e liberdade de todos os povos envolvidos.

A articulação entre os cursos em EAD e o currículo dos vários demandantes de formação (engenharias, tecnologias, artes, formação de professores, ou biologia ou comércio...) passa pela costura no âmbito da cultura digital (ALMEIDA; SILVA, 2014). A ampla demanda por cursos EAD atravessa duas variáveis: a formação ampla, rápida e de caráter focal por meio das tecnologias e a formação para a cultura digital. Essa se consubstancia, sobretudo, na apropriação de novas linguagens, pela ampliação da participação em redes mundiais, pela formação de habilidades para mudança rápida de tecnologias e valores. Ora, isso tudo pode ser denominado cultura digital. Mas a cultura digital não existe solta, como valor etéreo e sem conteúdos. Os conteúdos da cultura, do conhecimento humano e de valores éticos específicos são sempre enunciados e vividos. Nossa perspectiva é que seus conteúdos não sejam apenas dados pelo mercado, mas pelos projetos políticos das nações, pelo respeito ao contexto da cultura e dos valores latinoamericanos. É aqui que os conteúdos curriculares nacionais (ALMEIDA; FRANCO, 2014) e de integração internacionais marcam suas posições como 
articuladores dos programas de formação. Tais debates originadores das políticas curriculares se darão no diálogo entre nações e na internacionalização dos seus propósitos.

Todas essas mudanças e as discussões necessárias para sua implementação ganham destaque e importância nesse ambiente de expansão e internacionalização da educação brasileira no âmbito do MERCOSUL. Mudanças do tipo das descritas acima precisam ser discutidas de maneira institucionalizada e em rede entre todos os envolvidos - governos nacionais, SEM, instituições de ensino e empresas, fundamentais que são para fomento desse processo de mobilidade acadêmica, tanto em cursos de graduação como de pós-graduação e, mesmo, a adoção da educação a distância como fator de apoio e impulso a esse processo, como a adoção de um sistema de acreditação de cursos, o debate curricular, a avaliação da qualidade e validação dos estudos realizados por estudantes em outros países, o estabelecimento de critérios de avaliação baseados em competências.

\section{CONSIDERAÇÕES FINAIS}

O aumento da oferta de educação superior é processo claramente apoiado e realizado pelos governos em diversos países. Esse fenômeno tem a ver com o aumento do grau de exigência dos processos de democratização dos países em busca da escolarização das populações que ascendem cada vez mais a graus maiores de participação social, mas também se relaciona com a procura necessária por qualificação profissional, que se tem tornado, de igual modo, uma exigência crescente dos mercados de trabalho e de partilha dos bens culturais. Realizar essa expansão da educação superior, ao mesmo tempo em que se fomentam os processos de integração transnacionais, contribui, também, para o combate às desigualdades regionais de todas as ordens: econômicas, sociais ou educacionais. Exemplos de desenvolvimento de plataformas colaborativas entre os países do MERCOSUL são o caminho que já se traça para a cooperação concreta e fundamentada como o Programa MSUR (Cidades Metropolitanas), promovido pela Comissão Econômica para a América Latina e o Caribe (CEPAL), com vistas a formular proposições para uma nova agenda urbana estratégica, que incida sobre as agendas do MERCOSUL e, também, da União de Nações Sul-americanas (Unasul). As atividades resultantes de acordos bilaterais e gerais se realizam em forma de Colóquios, que visam a organizar as análises dos desafios e a encaminharlhes soluções construídas segundo metodologias dessa Comissão. Em setembro de 2015 já se previa o IV Colóquio Governo, Governança, Educação e Cultura, temas afeitos aos interesses formativos deste artigo. 
Um segundo terreno fértil, onde nascem cooperações latinoamericanas, é o espaço das cidades educadoras do Mercosul (Mercocidades Educadoras). Levantamentos de características regionais, assim como espaços de complementaridade de esforços e investimentos já estão traçados nesse programa de cooperação. Potencializar os empenhos já havidos na ordem de gestão e intercâmbios de formação docente e discente se revelam esperanças eficazes de curto e médio prazos.

Entende-se que a educação a distância pode ter papel destacado nesse processo de apoio à educação transnacional, por exemplo, com o aumento da oferta de vagas em cursos superiores de formação inicial ou continuada e, ainda, no apoio ao processo de mobilidade acadêmica. O Estado de São Paulo, no Brasil, desenvolveu plataforma colaborativa de formação de professores em cursos de especialização de 360h, em todas as áreas de conhecimento da Educação Básica, com ampla capacidade de atendimento (10.000 professores simultaneamente), que revelam eficácia e baixíssimo índice de abandono (Almeida; Cabral, 2011).

Para isso, há que se pensar em mecanismos que atendam não somente às necessidades acadêmicas da educação presencial, mas também às especificidades da educação a distância. Trabalhar a mobilidade virtual, por exemplo, requererá esforços conjuntos para aproveitar essa potencialidade da evolução tecnológica aplicada à educação.

Como no processo de integração educacional acontecido na Europa, por intermédio do Processo de Bolonha, vemos acontecer no âmbito da América do Sul processo parecido, reverberado pelo Setor Educacional do MERCOSUL (SEM), que vem organizando e dirigindo esforços na condução desse projeto entre os Estados membros do MERCOSUL.

Nesse cenário de alargamento da oferta de educação superior, algumas medidas se fazem necessárias e já estão em curso, conduzidas pela SEM. Entre elas, estão destacadas aqui a criação e expansão de um processo de acreditação internacional de cursos e o estímulo a um efetivo sistema de mobilidade estudantil, políticas que exigem o debate e a perspectiva de bases curriculares transnacionais. Contudo, ainda outras medidas precisam ser tomadas e estimuladas, tanto no âmbito das políticas públicas nacionais e internacionais como no campo da gestão administrativa e pedagógica das instituições de ensino.

Dessa forma, para que haja expansão e integração educacional é necessário um trabalho conjunto realizado por todas as partes envolvidas no processo, ou seja, SEM, governos nacionais, organismos internacionais, instituições de ensino e, também, agentes representantes dos mercados de trabalho, para que sejam tratadas, de maneira estratégica, democrática e humanamente criativa, as diversas e 
complexas questões que envolvem a educação universitária e a formação contínua de identidades e a multiculturalidade em nossos países.

\section{REFERÊNCIAS}

ALMEIDA, F. J.; CABRAL, V. L. (org.). Quantidade é qualidade. São Paulo: Fundação Padre Anchieta. (Escola de Formação de Professores Paulo Renato Souza), 2011.

ALMEIDA, F. J.; FRANCO, M. G. Tecnologias para a Educação e Políticas curriculares de Estado. In: BARBOSA, A. F. Pesquisa sobre o uso das tecnologias de informação e comunicação nas escolas brasileiras. TIC Educação, 2013. São Paulo: Comitê Gestor da Internet no Brasil, 2014.

ALMEIDA, F. J.; SILVA, Maria da Graça M. A cultura como direito e a cultura digital. Revista e-curriculum, São Paulo, v. 12, n.2, p. 1233-1247, 2014. Disponível em: <http://revistas.pucsp.br/Index.php/curriculum>

ALMEIDA, M.E.B. de; IANNONE, L.R.; SILVA, M.G.M da; VILLARINHOS, M.C.S. Educação a distância: oferta, características e tendências dos cursos de Licenciatura em Pedagogia. São Paulo: F.V.C., 2012.

BELLONI, M.L. Educação a distância. Campinas/SP: Autores Associados, 2012.

BRASIL. Ministério da Educação. Secretaria de Educação Superior. A democratização e expansão da educação superior no pais 2003-2014. Brasília: MEC/SESU. 2015. Disponível em: < http://portal.mec.gov.br/index. php?option $=$ com_content\&view $=$ article $\&$ id $=20954 \&$ Itemid $=1329>$

. Lei no 13.005, de 25 de junho de 2014. Aprova o Plano Nacional de Educação - PNE e dá outras providências. Diário Oficial da União. Brasília: Imprensa Nacional. 2014a.

. Relatório Educação para Todos no Brasil 2000-2015. Brasília: MEC, 2014b Disponível em www.mec.gov.br

. Decreto $\mathrm{n}^{\circ}$ 5.800, de 08 de junho de 2006. Dispõe sobre o Sistema Universidade Aberta do Brasil - UAB. Diário Oficial da União, Brasília, 09 jun. 2006.

646 - RBPAE - v. 31, n. 3, p. 627 - 648 set./dez. 2015 
. Decreto $\mathrm{n}^{\circ}$ 5.622, de 19 de dezembro de 2005. Regulamenta o art. 80 da Lei $\mathrm{n}^{\circ}$ 9.394, de 20 de dezembro de 1996, que estabelece as diretrizes e bases da educação nacional. Diário Oficial da União. Brasília: Imprensa Nacional, 2005.

Lei Diretrizes e Bases da Educação Nacional. Brasília: MEC, 2002.

EUROPEAN COMMISSION. Agência de Execução relativa à Educação, ao Audiovisual e à Cultura (EACEA). O Espaço Europeu de Ensino Superior em 2012: Relatório sobre a Implementação do Processo de Bolonha. Bruxelas: EACEA, 2013.

GIOLO, J. A educação a distância e a formação de professores. Educ. Soc. 2008, vol.29, n.105, p.1211-1234, 2008.

LEGORIA, L. Acreditación Universitaria en el MERCOSUR y la UE. Integración y Conocimiento. n.2, pp. 69-81, 2013.

MEC/INEP. Censo da Educação Superior 2012: resumo técnico. Brasília: INEP, 2014.

MERCOSUL. Setor Educacional do Mercosul (SEM). Plano de Ação do Setor Educacional do Mercosul 2011- 2015. Montevideu: SEM, 2012.

MERCOSUL. Indicadores Estadísticos del Sistema Educativo del Mercosur Sector Educativo del Mercosur (SEM); Sistema de Información y Comunicación del Mercosur Educativo (SIC); Montevideu: Grupo Gestor del Proyecto (GGP), 2009.

PRAXEDES, W.; PILETTI, N. O Mercosul e a sociedade global. $8^{\text {a }}$ ed. São Paulo: Ática, 1997.

. Mercosul, competitividade e educação. Estud. av. [online]. vol.12, n.34, pp. 219 233, 1998.

TEIXEIRA, A. Desconstruindo a Universidade: Modelos universitários emergentes mais abertos, flexíveis e sustentáveis. Revista de Educación a Distancia (RED), XI: 32, p. 1-13, 2012. 
.; MIRANDA, B.; DIAS, A. Virtual Mobility and the EQF: using e-learning to widen access and enhance quality higher education across Europe. In T. Bastiaens \& M. Ebner (Eds.), Proceedings of World Conference on Educational Multimedia, Hypermedia and Telecommunications (pp. 10031012). Chesapeake, VA: AACE, 2011.

WARLLEY FERREIRA SAHB é Licenciado em Matemática pela UNI BH em 2001, Mestrado em Educação pela PUC-MG (2005). Possui Especialização em Informática na Educação pela PUC-MG (2002). Doutorando em Educação na PUC-SP realizando estágio doutoral sanduíche na Universidade Aberta de Portugal (UAb). Atualmente é Técnico em Assuntos Educacionais da Universidade Federal de Lavras, lotado no Centro de Educação a Distância CEAD/UFLA, e Coordenador Pedagógico do CEAD, além de colaborar como docente em disciplinas de cursos de graduação e pós-graduação a distância. Ocupou também o cargo de Coordenador Adjunto da Universidade Aberta do Brasil na UFLA. E-mail:wfsahb@gmail.com

FERNANDO JOSÉ DE ALMEIDA possui graduação em Filosofia e Pedagogia pela Faculdade Nossa Senhora Medianeira (1970), mestrado em Educação: Filosofia, pela PUC-SP (1977) e doutorado em Educação: Filosofia, pela PUC-SP (1984). Pós-doutorado bolsa CNRS/CAPES, em Lyon, França (1987). Professor titular do curso de pós-graduação em Educação: Currículo da PUC-SP. Vice-Presidente da Fundação Padre Anchieta - rádios e TV educativas de São Paulo (2007-2010). Diretor de Currículo, Avaliação e Formação da Secretaria Municipal de Educação de São Paulo. E-mail: fernandoalmeida43@gmail.com

Recebido em abril de 2015 Aprovado em setembro de 2015 